\title{
UK and proliferation
}

SIR-Your leading articles, on 27 June, 18 and 25 July and 1 August, on the proliferation and safeguards implications of emergent nuclear technology and nuclear commerce and on arms control difficulties, all relate to the current Non-Proliferation (NPT) Treaty Review Conference and its likely success or failure. It is a consolation that Nature has given this conference and its attendant issues so much coverage, when the other science journals and current affairs journals have barely afforded NPT a mention.

I should like to comment further on one particular aspect you raised on 1 August, that of the nature of Euratom safeguards as applied to the United Kingdom. There is a continuing problem in that the United Kingdom government still refuses to admit safeguards inspectors from the International Atomic Energy Agency or Euratom to the Windscale Magnox reprocessing plant at Sellafield, on the grounds that nuclear material from both British Nuclear Fuels' military designated plants and the electricity boards' reactors are either co-processed or processed sequentially. This means that the physical inspection of the fissile material within the reprocessing plant is not possible; only book-keeping checks are allowed. Foreign governments, including that of the United States, must rely upon the honesty of the British government when it states that no swapping of civil to military plutonium takes place. There are no meaningful safeguards applied to plutonium in the United Kingdom.

That this is becoming an important issue is spelled out by former UK government energy consultant Ian Smart in the August 1985 issue of Nuclear Engineering International, in which he points out in a preview article for the NPT Review Conference that "there is rising pressure on the United States, Britain and France to draw a clearer line between all civil and military nuclear operations, especially in the fuel cycle, for example, by renouncing any military use of material obtained by reprocessing civil reactor fuel. That pressure may increase in the aftermath of the [NPT] Review Conference."

The British government told Parliament on 13 May that it had no intention of raising the problems of applying safeguards at Sellafield at the NPT Review Conference. It is not surprising. In the 70 parliamentary questions it has been asked specifically on plutonium since the beginning of the year, it has been less than forthcoming. Indeed, so parsimonious has it been with details, that one begins to wonder whether it has anything insidious to hide. One contrasting example will suffice to show the problem at its starkest.

On 15 January, the Secretary of State for Energy stated to Parliament that it was "not the practice" of the government to release details on the Mutual Defense Agreement on atomic energy matters signed between the United States and the United Kingdom. This agreement, dating from 1958, has enabled plutonium and highly enriched uranium and tritium to be exchanged across the Atlantic, as well as provided for other common nuclear weapons development. There are worries in some quarters that some of the plutonium sent from the United Kingdom was created in electricity board rather than military reactors, hence blurring the "atoms for peace" profile of nuclear energy.

On 23 May, however, when the government was asked for details of all the nuclear weapons tests carried out by or for the United Kingdom and the United States at the Nevada test site, their code names and whether conducted below or above ground, the government replied with full details, despite the fact that these tests were conducted under precisely the same 1958 Mutual Defense Agreement on which the government refuses to divulge details on fissile material exchanges.

To the outsider, it seems that something odd may be happening. It would be in the interests of all that the United Kingdom government should fully explain its position before or at the NPT Review Conference. The patience of the non-nuclear states over the antics of the nuclear weapons states aiding each others' armouries surely has only limited life before it snaps. Then we will witness the collapse of the non-proliferation regime.

\section{European Proliferation \\ Information Centre,}

258 Pentonville Road,

London N1 9JY, UK

\section{Down with metric}

SIR-I agree with Dr D.C. Jolly (Nature 8 August, p.480) about the demerits of the metric system.

The metre is now defined as the distance travelled by light, in vacuo, in 1/299 792458 second. This seems to me an absurd number to choose - its only merit is that it preserves the metre as the basis of the SI system. If we were to start afresh, defining the speed of light instead of measuring it, we would surely choose a more convenient number such as $3 \times 10^{8}$, or even better $10^{\circ}$. The latter would have the advantage that the new unit of length would be very close to the foot (about $11 / 2$ per cent shorter) and this I feel opens the way to a rehabilitation of the pre-SI units.

The realization that light travels at almost exactly $10^{9} \mathrm{ft} \mathrm{s}^{-1}$ prompted me to investigate whether there is any system of units (metric, imperial or otherwise) that gives values close to integral powers of ten for the fundamental constants $c, G$ and $h$ (or $\hbar)$. Preliminary work on the rod-grain system was fairly encouraging but failed to find a sensible unit of time. However, when the strict requirement on units being powers of ten was relaxed to include sensible multipliers (i.e. not 3 and certainly not 2.99792458), it turns out that the footpound-second system works splendidly. In the relevant units, $c=9.8 \times 10^{8}, G=$ $1.07 \times 10^{-9}$ and $4 \hbar=1.001 \times 10^{-32}$

If we choose a system of units in which $c$ $=10^{9}, G=10^{-9}$ and $4 \hbar=10^{-32}$ (all exactly), the units would be 1 new foot (or whatever) $=1.060$ old feet, 1 new pound $=0.960$ old pounds and 1 new second $=1.078$ old seconds. I foresee no problems in introducing new feet and new pounds - we have coped remarkably well, all things considered, with the horrible metre and kilogram - but the new second may be something of a nuisance (clocks, calendars, etc.). However, the Earth's rotation is well known to be slowing down and the length of the day is increasing by roughly 8 seconds every million years. Thus, one day will contain 86,400 new seconds in about 800 million years' time. Perhaps we should delay the counter-revolution in our adopted system of units for a while.

University of Cambridge,

W.G. REES

Department of Physics,

Cavendish Laboratory,

Cambridge CB3 OHE, UK

\section{Pain in animals}

SIR-The view expressed by Robert Sharp (Nature 25 July, p.290), that it is impossible to assess pain in laboratory animals, is not likely to be accepted by those who study this particular problem nor by those called upon to perform the task, including most members of the veterinary profession.

Although it may be said to be "impossible" to find guidelines for the assessment of pain that guarantee agreement on the degree of severity, guidelines are used and are being constantly improved. In most cases, in applying such guidelines, significant disagreement is unlikely, except perhaps on the distinction mild/moderate and moderate/severe pain, which may be resolved by taking the opinions of others experienced with the species involved.

In order to maintain and improve the health and welfare of animals and man, it continues to be necessary to subject some animals to experimental procedures. Unfortunately, it appears that those who are concerned about such use of animals are not always willing to accept that, despite the interferences sanctioned under licence as part of a procedure, the welfare of the animals concerned is and will remain, the first priority of those who carry out this work. V. MOLONY

Department of Veterinary Physiology,

University of Edinburgh,

Royal (Dick) School of Veterinary Studies, Summerhall, Edinburgh EH91QH, UK 